\title{
A Simple Equation to Estimate Urinary Flow Rate Using Urine Creatinine
}

\author{
Luke Webster $^{\mathrm{a}} \quad$ Brett Larive $^{\mathrm{b}} \quad$ Jennifer Gassman ${ }^{\mathrm{b}} \quad$ Alexander Bullen $^{\mathrm{a}}$ \\ Steven D. Weisbord ${ }^{c, d}$ Paul M. Palevskyc, d Linda F. Fried ${ }^{c, d} \quad$ Kalani Raphael $^{e, f}$ \\ Tamara Isakova ${ }^{g}$ Joachim $\mathrm{H} . \mathrm{Ix}^{\mathrm{a}} \mathrm{h}_{\mathrm{h}} \mathrm{i}$ \\ a Division of Nephrology-Hypertension, Department of Medicine, University of California San Diego, San Diego, CA \\ USA; ${ }^{b}$ Department of Quantitative Health Sciences, Cleveland Clinic, Cleveland, $\mathrm{OH}, \mathrm{USA} ;{ }^{\mathrm{C}}$ Renal Section, Veterans \\ Affairs Pittsburgh Healthcare System, Pittsburgh, PA, USA; 'Division of Nephrology, Department of Medicine, \\ University of Pittsburgh, Pittsburgh, PA, USA; ' Veterans Affairs Salt Lake City Healthcare System, Salt Lake City, UT, \\ USA; ${ }^{\mathrm{f}}$ Division of Nephrology and Hypertension, University of Utah, Salt Lake City, UT, USA; ${ }^{9}$ Division of Nephrology \\ and Hypertension, Department of Medicine and Center for Translational Metabolism and Health, Institute for Public \\ Health and Medicine, Northwestern University Feinberg School of Medicine, Chicago, IL, USA; hephrology Section, \\ Veterans Affairs San Diego Healthcare System, La Jolla, CA, USA; 'Division of Preventive Medicine, Department of \\ Family Medicine and Public Health, University of California San Diego, San Diego, CA, USA
}

\section{Keywords}

Urine volume $\cdot$ Kidney disease $\cdot$ Prediction $\cdot$ Creatinine

\begin{abstract}
Background: Accurate assessment of urine flow remains challenging in both inpatient and outpatient settings. We hypothesized we could derive an equation that would accurately estimate urine flow rate $(\mathrm{eV})$ through derivation from other existing equations commonly used in nephrology clinical practice. Methods: The eV equation was derived using the Cockcroft-Gault and the measured creatinine clearance $\left(\mathrm{CrCl}=\mathrm{U}_{\mathrm{Cr}} \mathrm{V} / \mathrm{P}_{\mathrm{Cr}}\right)$ equations. Within the African American Study of Kidney Disease and Hypertension (AASK; $n=570$ ) and COMBINE $(n=133)$ clinical trials, we identified participants with concordant estimated and measured creatinine excretion rates to define a subset with highly accurate $24-\mathrm{h}$ urine collections, to assure a reliable gold standard. We then compared $\mathrm{eV}$ to measured 24-h urine flow rates in these trials. Results: In AASK, we found a high correlation between
\end{abstract}

(c) 2020 S. Karger AG, Basel

karger@karger.com

www.karger.com/ajn
$\mathrm{eV}$ and measured urine flow rate $(\mathrm{V} ; r=0.91, p<0.001)$; however, Bland-Altman plots showed that eV was $9.5 \mathrm{~mL} / \mathrm{h}$ lower than $\mathrm{V}$, on average. Thus, we added a correction factor to the $\mathrm{eV}$ equation and externally validated the new equation in COMBINE. $\mathrm{eV}$ and $\mathrm{V}$ were again highly correlated $(r=0.91$, $p<0.001$ ), and bias was improved (mean difference 5.3 $\mathrm{mL} / \mathrm{h}$ ). Overall, $80 \%$ of individuals had $\mathrm{eV}$ that was within $20 \%$ of V. Conclusions: A simple equation using urine creatinine, demographics, and body weight can accurately predict urine flow rate and may have clinical utility in situations where it is difficult to accurately measure the urine flow rate.

(c) 2020 S. Karger AG, Basel

\section{Introduction}

Accurate assessment of urine flow rate (volume per unit time) is a common clinical necessity in both inpatient and outpatient settings and is essential for evaluating volume status; excretion of a myriad of nutrients, minerals, 
and hormones; and measurement of kidney function and proteinuria. Yet its assessment remains challenging. In outpatients, assessment requires detailed patient instructions that are difficult for many to perform, and even when done accurately, the clinician is often uncertain whether an individual patient may have over- or undercollected their timed urine collection. In inpatients, urine may be discarded without knowledge of staff, and often the estimated daily intake and output provided by the nursing staff correlate poorly with body weight changes. These factors lead to considerable uncertainties in clinicians who rely on these data for clinical decision making. Novel methods to estimate urine flow rate $(\mathrm{eV})$ that are safe, easy to implement, accurate, readily available, and reproducible would have immediate clinical utility.

We noted that the measured creatinine clearance (CrCl; UV/P) and the Cockcroft-Gault formulas [1] could be combined and rearranged to provide an estimate of urine flow rate. We sought to derive an equation using a single measurement of urine creatinine and demographics and test its accuracy.

\section{Materials and Methods}

We began with the equation for measured $\mathrm{CrCl}$ (urine creatinine $[\mathrm{U}] \times$ urine flow rate $[\mathrm{V}] /$ plasma creatinine $[\mathrm{P}]$ ) and the Cockcroft-Gault equation [1] and derived an equation to $\mathrm{eV}$. The equation was validated by applying it to African American Study of Kidney Disease and Hypertension (AASK), and COMBINE trial participants. The participant characteristics and methods of these trials have been described previously [2-4]. The present study uses data from the run-in phase of these studies, prior to randomization. In each case, participants were provided detailed instructions on voiding to an empty bladder and asked to collect all urine generated over $24 \mathrm{~h}$, maintain in refrigeration, and return it to study personnel subsequently. Participants' 24 h urine specimens served as our gold standard for comparison, but in order to minimize inherent errors induced during collection, we used a previously validated equation to estimate creatinine excretion rate [5]. We compared the measured creatinine excretion in the timed urine specimens versus estimated creatinine excretion rate, and subjects with discordant estimated and measured levels by $>20 \%$ were excluded. We developed scatter plots comparing estimated to measured urine flow rates and calculated pairwise correlations and Bland-Altman plots [6]. The mean difference between these variables serves as the primary indicator of bias. We multiplied the SD of the mean difference by \pm 1.96 to define the $95 \%$ limits of agreement (LoA), which served as the primary estimate of precision. Finally, we calculated the percent of estimated flow rates that fell within 10,20, and $30 \%$ of measured urine flow rates; these percentages served as the primary indicator of overall accuracy. After completing this evaluation in AASK, we noted a moderate bias in the eV leading to a post hoc correction. This new equation was then tested in the COMBINE trial. All participants provided written informed consent. All analyses were conducted in Stata/SE version 11.2 (Stata Corporation, College Station, TX, USA). Additional information on materials and methods are available in online supplementary Materials (see www.karger.com/doi/10.1159/000506728).

\section{Results}

\section{Equation Derivation}

We began with the standard equation to measure $\mathrm{CrCl}$ as depicted in equation $\mathrm{A}$ below, where $\mathrm{CrCl}=$ creatinine clearance $(\mathrm{mL} / \mathrm{min}), \mathrm{UCr}=$ urine creatinine concentration $(\mathrm{mg} / \mathrm{dL}), \mathrm{V}=$ urine flow rate $(\mathrm{mL} / \mathrm{min})$, and $\mathrm{PCr}=$ plasma creatinine concentration $(\mathrm{mg} / \mathrm{dL})$. While this equation is traditionally used as an estimate of glomerular filtration rate, it contains a term for urine flow rate $(V)$. Thus, if other inputs were known, the equation could be repurposed to estimate $\mathrm{V}$.

$$
\mathrm{CrCl}\left(\frac{\mathrm{mL}}{\min }\right)=\frac{\mathrm{UCr} \times \mathrm{V}}{\mathrm{PCr}}
$$

$\mathrm{CrCl}$ can also be estimated by the Cockcroft-Gault equation (equation B)

$$
\operatorname{CrCl}\left(\frac{\mathrm{mL}}{\min }\right)=\frac{[(140-\text { age }(\text { years })) \times \mathrm{wt}[\mathrm{kg}] \times(0.85 \text { if female })]}{72 \times \operatorname{PCr}\left(\frac{\mathrm{mg}}{\mathrm{dL}}\right)}
$$

Substituting the Cockcroft-Gault equation into equation $\mathrm{A}$ provides equation $\mathrm{C}$, below. Note that urine flow rate $(\mathrm{V})$ has been renamed " $\mathrm{eV}$ " in equation $\mathrm{C}$, as urine flow rate is now estimated rather than directly measured:

$$
\frac{\mathrm{UCr}\left(\frac{\mathrm{mg}}{\mathrm{dL}}\right) \times \mathrm{eV}\left(\frac{\mathrm{mL}}{\mathrm{min}}\right)}{\operatorname{PCr}\left(\frac{\mathrm{mg}}{\mathrm{dL}}\right)}=\frac{[(140-\mathrm{age}) \times \mathrm{wt}(\mathrm{kg}) \times(0.85 \text { if female })]}{72 \times \operatorname{PCr}\left(\frac{\mathrm{mg}}{\mathrm{dL}}\right)}
$$

Solving for urine flow rate $(\mathrm{eV})$ provides equation $\mathrm{D}$ :

$$
\mathrm{eV}\left(\frac{\mathrm{mL}}{\mathrm{min}}\right)=\frac{\operatorname{PCr}\left(\frac{\mathrm{mg}}{\mathrm{dL}}\right) \times[(140-\mathrm{age}) \times \mathrm{wt}(\mathrm{kg}) \times(0.85 \text { if female })]}{\mathrm{UCr}\left(\frac{\mathrm{mg}}{\mathrm{dL}}\right) \times \operatorname{PCr}\left(\frac{\mathrm{mg}}{\mathrm{dL}}\right) \times 72}
$$

Plasma creatinine is now found in the numerator and denominator and can be cancelled, thereby eliminating the need for serum creatinine measurement for 
Table 1. Baseline characteristics of AASK and COMBINE trial participants stratified by median urine flow rates

\begin{tabular}{|c|c|c|c|c|}
\hline & $\begin{array}{l}\text { urine flow rate } \\
<\text { median }(n=289)\end{array}$ & $\begin{array}{l}\text { urine flow rate } \\
\geq \text { median }(n=281)\end{array}$ & $\begin{array}{l}\text { urine flow rate } \\
<\text { median }(n=62)\end{array}$ & $\begin{array}{l}\text { urine flow rate } \\
\geq \text { median }(n=61)\end{array}$ \\
\hline Age, years, mean \pm SD & $55 \pm 11$ & $54 \pm 11$ & $71 \pm 9$ & $64 \pm 11$ \\
\hline Gender, female, $n(\%)$ & $113(39)$ & $102(36)$ & $24(40)$ & $21(34)$ \\
\hline Black, $n(\%)$ & $289(100)$ & $281(100)$ & $15(24)$ & $15(25)$ \\
\hline $\mathrm{BMI}, \mathrm{kg} / \mathrm{m}^{2}$, mean $\pm \mathrm{SD}$ & $29.6 \pm 6.2$ & $31.4 \pm 6.7$ & $29.3 \pm 5.6$ & $32.0 \pm 6.8$ \\
\hline \multicolumn{5}{|l|}{ CKD etiology, $n(\%)$} \\
\hline Diabetes & 0 & 0 & $19(31)$ & $26(43)$ \\
\hline Hypertension & $289(100)$ & $281(100)$ & $15(24)$ & $9(15)$ \\
\hline Glomerulonephritis & 0 & 0 & $3(5)$ & $5(8)$ \\
\hline $24-\mathrm{H}$ urine volume, $\mathrm{mL} / \mathrm{h}$, mean $\pm \mathrm{SD}$ & $70 \pm 15$ & $121.0 \pm 28.2$ & $60 \pm 12$ & $111 \pm 25$ \\
\hline
\end{tabular}

AASK, African American Study of Kidney Disease and Hypertension; BMI, body mass index; CKD, chronic kidney disease; eGFR, estimated glomerular filtration rate; IQR, interquartile range; ACR, albumin to creatinine ratio.

$\mathrm{eV}$ estimation. Next, since $\mathrm{eV}$ is expressed in milliliters per minute in equation $\mathrm{D}$ and urine flow rate is more commonly utilized in milliliters per hour in clinical practice, we multiplied by 60 as depicted in equation $\mathrm{E}$ :

$$
\mathrm{eV}\left(\frac{\mathrm{mL}}{\mathrm{h}}\right)=\frac{[(140-\text { age }) \times \mathrm{wt}(\mathrm{kg}) \times(0.85 \text { if female }) \times 60]}{\mathrm{UCr}\left(\frac{\mathrm{mg}}{\mathrm{dL}}\right) \times 72}
$$

Simplifying the fraction of the 2 constants on the righthand side (60 and 72) gives our equation for $\mathrm{eV}$ in equation F:

$$
\mathrm{eV}\left(\frac{\mathrm{mL}}{\mathrm{h}}\right)=\frac{[(140-\text { age }) \times \mathrm{wt}(\mathrm{kg}) \times(0.85 \text { if female }) \times 0.833]}{\mathrm{UCr}\left(\frac{\mathrm{mg}}{\mathrm{dL}}\right)}
$$

This equation was carried forward for validation in the AASK trial.

\section{Equation Validation in AASK}

Among 1,090 individuals within AASK with available urine collections, 570 (52\%) had concordant measured and estimated creatinine excretion rates within $20 \%$ and were included in this analysis. These participants had mean age of 55 years, $62 \%$ were male, all were AfricanAmerican, and none had diabetes by trial design (Table 1). The mean measured urine flow rate (V) in AASK was $94.9 \pm 34.2 \mathrm{~mL} / \mathrm{h}$, and mean estimated urine flow using equation $\mathrm{F}$ was $85.3 \pm 34.9 \mathrm{~mL} / \mathrm{h}$. These 2 measures were highly correlated with one another $(r=0.91, p<0.001$; Fig. 1). Bland-Altman analysis demonstrated that $\mathrm{eV}$ was systematically lower than $\mathrm{V}$ by $9.5 \mathrm{~mL} / \mathrm{h}$, on average, and the $95 \%$ LoA were $\pm 29.0 \mathrm{~mL} / \mathrm{h}$ (Fig. 2). We evaluated the percentage of $\mathrm{eV}$ values that were within percentiles of $\mathrm{V}$, as an indication of overall accuracy, and found that 36,71 , and $93 \%$ of eVs were within 10,20 , and $30 \%$ of $\mathrm{V}$, respectively.

Post hoc, we added a correction factor to the eV equation to account for the $9.5 \mathrm{~mL} / \mathrm{h}$ mean bias in AASK. The resulting equation $\mathrm{G}$ is shown below:

$$
\mathrm{eV}\left(\frac{\mathrm{mL}}{\mathrm{h}}\right)=9.5+\frac{[(140-\text { age }) \times \mathrm{wt}(\mathrm{kg}) \times(0.85 \text { if female }) \times 0.833]}{\mathrm{UCr}\left(\frac{\mathrm{mg}}{\mathrm{dL}}\right)}
$$

Had this equation been used, the mean bias would be zero, by definition, in AASK, the 95\% LoA would remain unchanged $( \pm 29 \mathrm{~mL} / \mathrm{h})$, but overall precision was improved with the percentage of eVs within 10,20 , and $30 \%$ of Vs are 46,79 , and $92 \%$, respectively. 


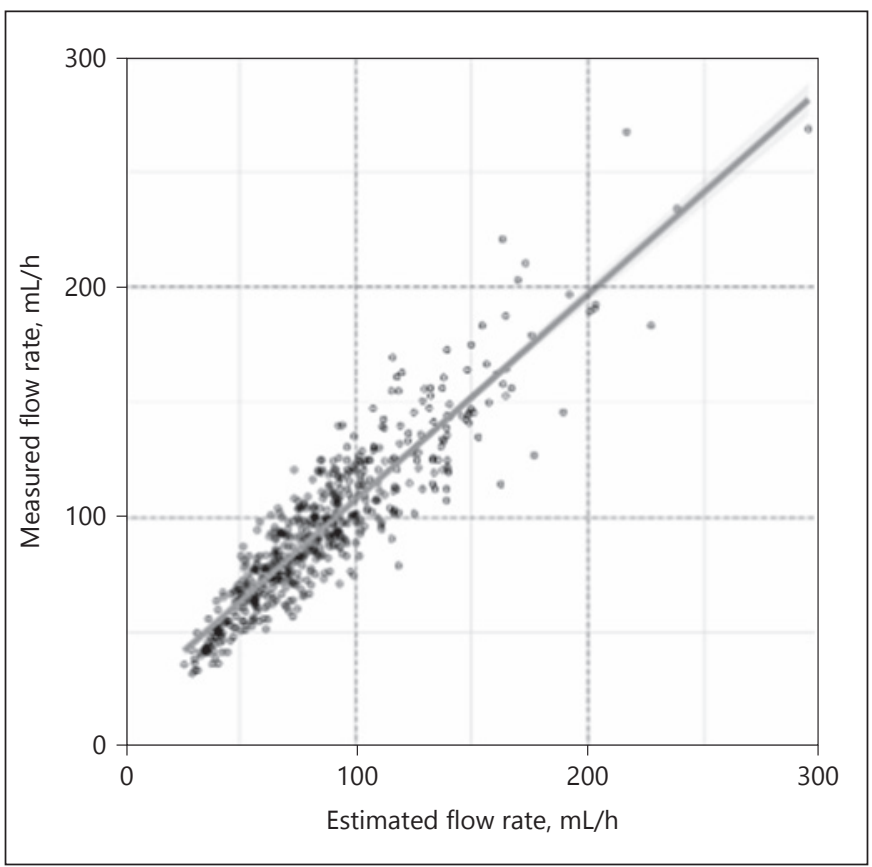

Fig. 1. Correlation of measured vs. estimated urine flow rate $(\mathrm{eV})$ using equation $\mathrm{F}$ in AASK. Figure shows the correlation of measured flow rate vs. estimated flow rate using equation $\mathrm{F}$ in AASK trial participants who had measured creatinine excretion rates within $20 \%$ of estimated creatinine excretion rates $(n=540) . r=$ $0.91, p<0.001$. AASK, African American Study of Kidney Disease and Hypertension.

External Equation Validation in the COMBINE Trial One hundred twenty-three (60\%) of the 205 COMBINE trial participants had measured and estimated creatinine excretion rates within $20 \%$ of one another. These participants had mean age of 68 years, $63 \%$ were male, and $25 \%$ were African-American (Table 1). We evaluated equation $\mathrm{G}$ in COMBINE, incorporating the correction factor derived in AASK. Using this equation, the correlation between $\mathrm{eV}$ and $\mathrm{V}$ was once again very high $(r=0.91$; Fig. 3); however, the mean bias was diminished; $\mathrm{eV}$ was $5.3 \mathrm{~mL} / \mathrm{h}$ lower, on average, than $\mathrm{V}$, with $95 \% \mathrm{LoA} \pm 26.1$ $\mathrm{mL} / \mathrm{h}$ in COMBINE (Fig. 4). The overall accuracy was improved with equation $\mathrm{G}$ with 43,80 , and $93 \%$ of eVs falling within 10,20 , and $30 \%$ of Vs, respectively.

The purpose of limiting the study sample to the subsets with highly correlated estimated and measured creatinine excretion rates was to define a subset of individuals with highly accurate $24 \mathrm{~h}$ urine collections to provide a reliable gold standard. Without this exclusion, we anticipated that bias (mean difference between $\mathrm{eV}$ and $\mathrm{V}$ ) would be similar, but that accuracy (the 95\% LOAs) would be wider, due to added variability in the gold stan-

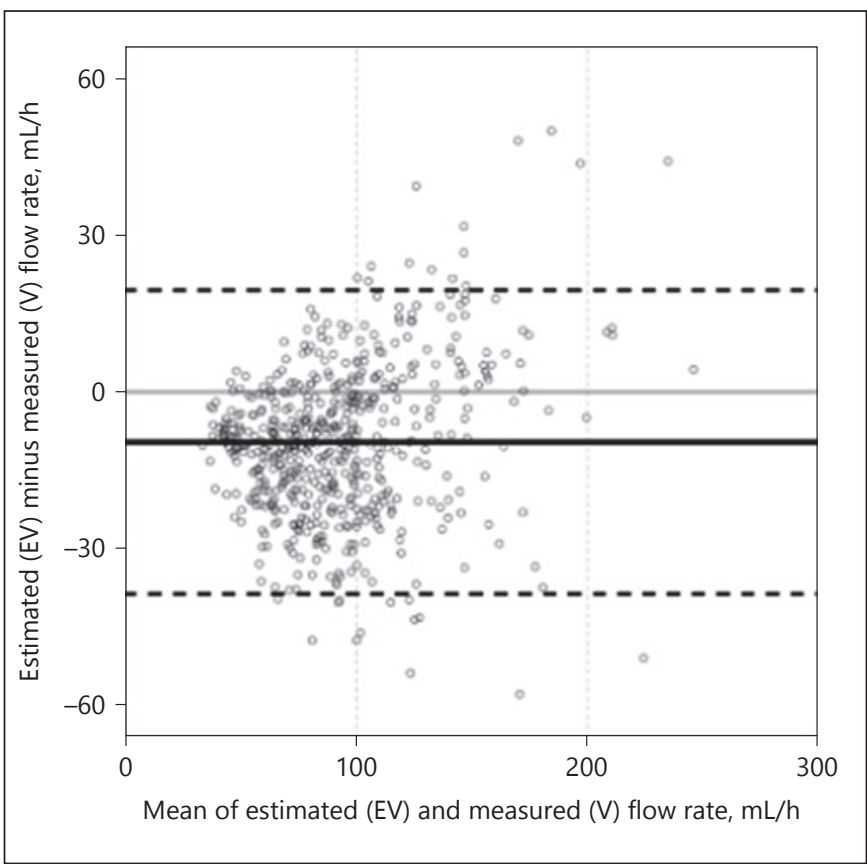

Fig. 2. Bland-Altman plot of estimated urine flow rate $(\mathrm{eV})$ using equation $\mathrm{F}$ vs. measured urine flow rate in AASK. Figure shows the mean bias $(-9.5 \mathrm{~mL} / \mathrm{h})$ and $95 \% \operatorname{LoA}(-38.2,+19.2 \mathrm{~mL} / \mathrm{h})$ of equation $\mathrm{F}$ relative to measured urine flow rate in AASK trial participants who had measured creatinine excretion rates within $20 \%$ of estimated creatinine excretion rates $(n=540)$. AASK, African American Study of Kidney Disease and Hypertension.

dard by over- and under-collected $24 \mathrm{~h}$ urine collections. To test this, we reevaluated the performance of equation $\mathrm{G}$ in COMBINE including all 205 study participants without any exclusions based on creatinine excretion. In this analysis, $\mathrm{eV}$ was $2.3 \mathrm{~mL} / \mathrm{h}$ lower than $\mathrm{V}$, thus slightly better than in the main restricted analysis. However, accuracy was much worse, with $95 \%$ LoA of $63.6 \mathrm{~mL} / \mathrm{h}$, likely due to greater variability in over- and under-collected urine collections included in the gold standard.

The final equation $\mathrm{G}$ for urine creatinine in both $\mathrm{mg} /$ $\mathrm{dL}$ and $\mu \mathrm{mol} / \mathrm{L}$ are shown in Figure 5.

\section{Discussion}

We derived a simple equation to estimate urine flow, $\mathrm{eV}$. Due to the nature of the inputs, plasma creatinine could be eliminated, such that the new equation requires only urine creatinine measurement and age, gender, and body weight. The $\mathrm{eV}$ estimates were highly correlated with measured urine flow rates in AASK participants, but under-estimated urine flow rate by $9.5 \mathrm{~mL} / \mathrm{h}$. We there- 


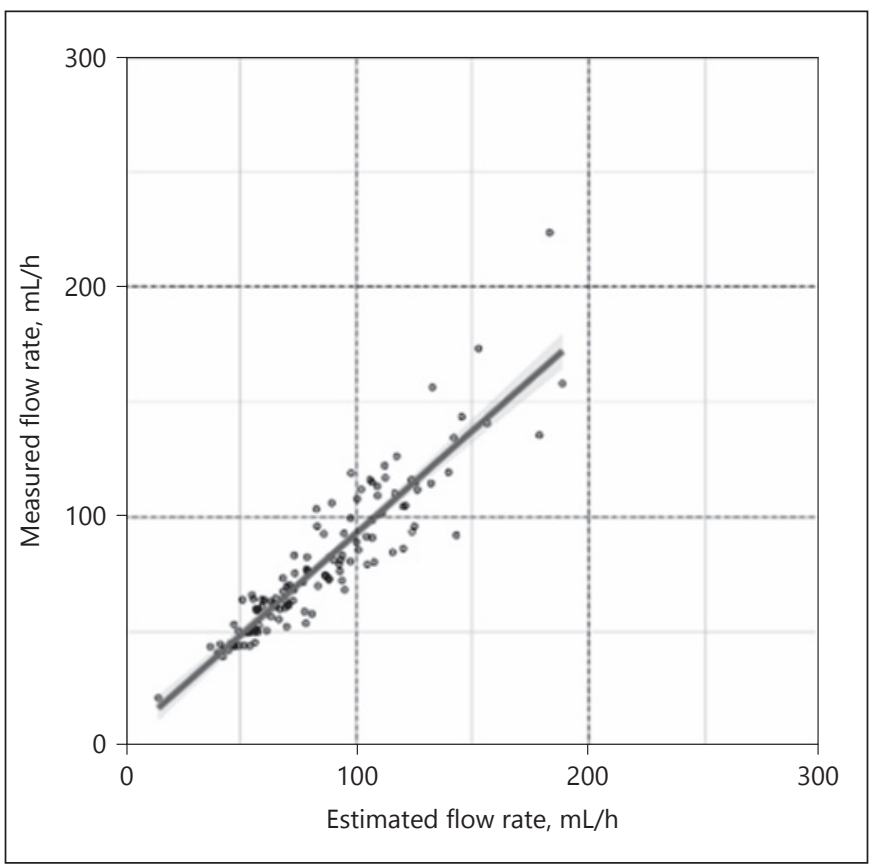

Fig. 3. Correlation of measured vs. estimated urine flow rate $(\mathrm{eV})$ using equation $\mathrm{G}$ in COMBINE. Figure shows the correlation of measured flow rate relative to estimated flow rate using equation $\mathrm{G}$ in COMBINE trial participants who had measured creatinine excretion rates within $20 \%$ of estimated creatinine excretion rates $(n=123) . r=0.91, p<0.001$.

fore applied a post hoc correction, adding back the 9.5 $\mathrm{mL} / \mathrm{h}$ underestimate, and validated the new equation in the COMBINE trial. The equation remained highly correlated with measured urinary flow rates and underestimated urine flow rate by $5.3 \mathrm{~mL} / \mathrm{h}$ in COMBINE. With this equation, $80 \%$ of $\mathrm{eV}$ estimates fell within $20 \%$ of the measured flow rates, and nearly half were within $10 \%$. Thus, we put forward the equations shown in Figure 5 (using urine creatinine in $\mathrm{mg} / \mathrm{dL}$ or $\mu \mathrm{mol} / \mathrm{L}$ ) as a simple method to estimate urine flow rate when urine collections are not possible, impractical, or of uncertain accuracy.

We envision that this new tool may be useful in several different clinical scenarios. For example, increasing fluid intake is a common treatment recommendation for nephrolithiasis. Monitoring eV at sequential clinic visits could allow assessment of adherence. Clinical trials are evaluating fluid intake to prevent chronic kidney disease (CKD) progression, and $\mathrm{eV}$ may provide a simple way to monitor adherence and separation of randomized treatment arms. Outpatient hydration protocols are frequently used in patients undergoing radiocontrast imaging studies and chemotherapy to prevent acute kidney injury. How often, and how well, these protocols are followed by patients is uncer-

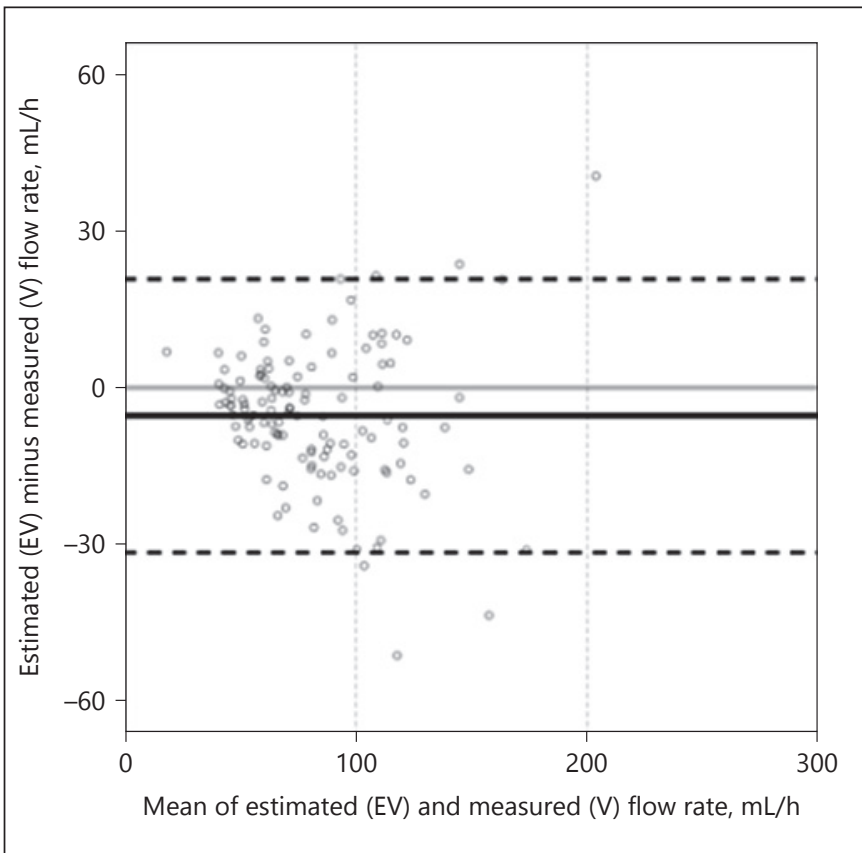

Fig. 4. Bland-Altman plot of estimated urine flow rate (eV) using equation $G$ vs. measured urine flow rate in COMBINE. Figure shows the mean bias $(-5.3 \mathrm{~mL} / \mathrm{h})$ and $95 \% \operatorname{LoA}(-31.4,+20.8$ $\mathrm{mL} / \mathrm{h}$ ) of equation $\mathrm{G}$ relative to measured urine flow rate in COMBINE trial participants who had measured creatinine excretion rates within $20 \%$ of estimated creatinine excretion rates $(n=123)$.

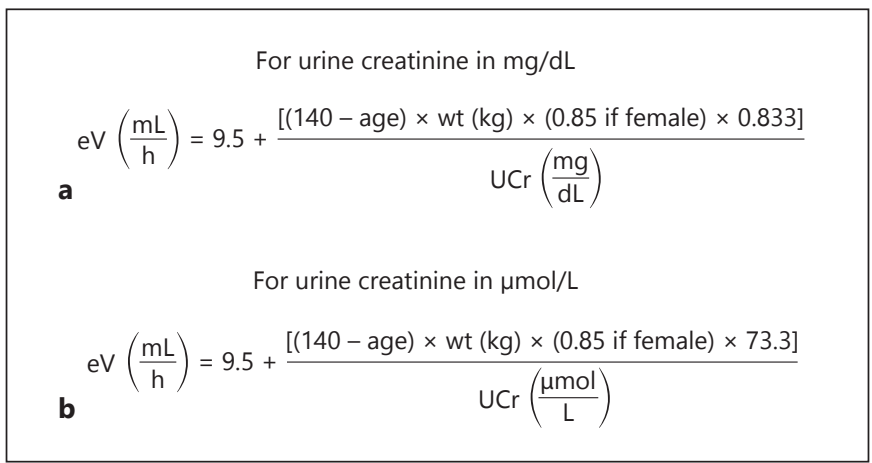

Fig. 5. Equations to estimate urine flow rate $(\mathrm{eV})$ using urine creatinine in $\mathrm{mg} / \mathrm{dL}$ (a) or $\mu \mathrm{mol} / \mathrm{L}$ (b). Equations are identical and correspond to "equation G" for urine creatinine in $\mathrm{mg} / \mathrm{dL}$ (a), and the same equation after conversion of units to accommodate urine creatinine concentrations in $\mu \mathrm{mol} / \mathrm{L}$ (b). UCr, urine creatinine concentration.

tain. $\mathrm{eV}$ could be measured on presentation, and those with low $\mathrm{eV}$ may benefit from additional fluids before performing the procedure. Future studies are needed to evaluate these uses of the $\mathrm{eV}$ equation. This study has important limitations. While estimated and measured flow rates 
were highly correlated, our first equation underestimated urine flow by $9.5 \mathrm{~mL} / \mathrm{h}$. A correction factor was added and resulted in less, but still evident, systematic bias $(5 \mathrm{~mL} / \mathrm{h})$, in an external validation sample. We validated the equation in persons with CKD. While assessment of urine flow rate is particularly common in $\mathrm{CKD}$, the $\mathrm{eV}$ equation will likely also have utility in non-CKD patients. Future studies are needed to validate the $\mathrm{eV}$ equation in other settings.

In conclusion, we have derived and validated a simple equation that estimates urine flow rate using only urine creatinine concentration and several readily available demographic variables. The equation may have utility to facilitate clinical decision making by overcoming ambiguity about the accuracy of timed urine volumes.

\section{Acknowledgment}

None.

\section{Disclosure Statement}

Dr. Joachim H. Ix is Principal Investigator of an Investigator Initiated Research Grant from Baxter International. All other authors report no disclosures.

\section{Funding Sources}

This study was supported by grants from the National Institutes of Diabetes and Digestive and Kidney Diseases (NIDDK; K24DK110427) and an American Heart Association Established Investigator Award (14EIA18560026) to J.H.I. Dr. Alexander L. Bullen was supported by a Ruth L. Kirschstein training grant from the NIDDK (T32DK104717). The COMBINE trial was sponsored by the NIDDK Pilot Clinical Trials consortium (contracts U01DK097093, U01DK099877, U01DK099924, U01DK099930, and U01DK099933) with additional support from R01DK102438.

\section{Author Contributions}

Dr. Joachim H. Ix is the primary investigator for this project; he assisted in project development, result analysis, manuscript preparation, and editing. Dr. Luke Webster, as a lead author of this project, assisted with data collection, data analysis, result analysis, manuscript preparation, and editing. Brett Larive was the lead statistician on this project and assisted with statistical analysis, table formulation, and manuscript editing. Drs. Jennifer Gassman, Alexander Bullen, Steven D. Weisbord, Paul M. Palevsky, Linda F. Fried, Kalani Raphael, and Tamara Isakova all assisted with manuscript preparation and editing. The results presented in this paper have not been published previously in whole or part, except in abstract form.

\section{References}

1 Cockcroft DW, Gault MH. Prediction of creatinine clearance from serum creatinine. Nephron. 1976;16(1):31-41.

2 Appel LJ, Middleton J, Miller ER 3rd, Lipkowitz M, Norris K, Agodoa LY, et al. The rationale and design of the AASK cohort study. J Am Soc Nephrol. 2003 Jul;14(7 Suppl 2):S166-72.

3 Isakova T, Ix JH, Sprague SM, Raphael KL, Fried L, Gassman JJ, et al. Rationale and Ap- proaches to Phosphate and Fibroblast Growth Factor 23 Reduction in CKD. J Am Soc Nephrol. 2015 Oct;26(10):2328-39.

4 Ix JH, Isakova T, Larive B, Raphael KL, Raj DS, Cheung AK, et al. Effects of Nicotinamide and Lanthanum Carbonate on Serum Phosphate and Fibroblast Growth Factor-23 in CKD: the COMBINE Trial. J Am Soc Nephrol. 2019 Jun;30(6):1096-108.
5 Ix JH, Wassel CL, Stevens LA, Beck GJ, Froissart $\mathrm{M}, \mathrm{Navis} \mathrm{G}$, et al. Equations to estimate creatinine excretion rate: the $\mathrm{CKD}$ epidemiology collaboration. Clin J Am Soc Nephrol. 2011 Jan;6(1):184-91.

6 Bland JM, Altman DG. Comparing methods of measurement: why plotting difference against standard method is misleading. Lancet. 1995 Oct;346(8982):1085-7. 